\title{
Effect of Operating Conditions and Screen Mesh Size on the Performance of Vermicomposting Bed with Automated Harvester and Watering System
}

\author{
Roger C. Montepio and Ryan M. Abenoja ${ }^{1}$
}

\begin{abstract}
\end{abstract}
This paper presents the development of a mechanical composting bed to reduce the drudgery of the existing vermiculture production through automation of watering and harvesting system. This study also determined the effect of moisture content level, sieving speed and mesh screen size on harvesting capacity and separation efficiency. The study was laid out in factorial experiment arranged in complete randomized design (CRD). The prototype consisted of a (1) composting bed with natural aeration and screen mesh at the bottom for automatic daily harvesting of vermicast and vermicomposting leachate (VCL), (2) automated watering sprinkler system, (3) vermicast and VCL storage beneath the composting bed, and (4) control system. During harvesting, composting bed is suspended in the main frame and is driven by an electric motor creating oscillating motion, thus sieving, separating the vermicast and leaving the worm in the bed. Analysis of Variance found that all factors significantly affected the harvesting capacity. However, there was no interaction effect among the three factors on harvesting capacity and separation efficiency. Highest harvesting capacity of $74.41 \mathrm{~g} / \mathrm{s}$ was obtained at 
lowest moisture content (40\%), largest sifter size (1/4) and highest speed (310 rpm). Highest separation efficiency of $32.33 \mathrm{~g} / \mathrm{s}$ was obtained at any moisture content) and largest sifter size (1/4). Daily cast and vermi leachate collected were $4 \mathrm{~kg}$ and 5 liters, respectively. An increase of 800 grams in worm population was recorded. The prototype had a BCR of 1.975 and IRR of $55 \%$ after 3 years of utilization.

Keywords: agricultural mechanization, vermicast, Vermicompost Leachate (VCL), worm casting

Vermiculture technology is emerging as an environmentally sustainable, economically viable and socially acceptable technology all over the world. The utilization of earthworms as waste managers for efficient composting of food and farm wastes and as soil managers for fertility improvement and enhanced farm production was known for ages but now it is being more scientifically and also commercially revived (Sinha, et al., 2010).

Waste degradation and composting by earthworms is proving to be an economically and environmentally preferred technology over the conventional microbial degradation and composting technology. It is a rapid, odorless process that reduces composting time more than half of the expected. The end product is both disinfected and detoxified (Edwards, 1998).

Vermicomposting in recent years has gained importance because of its higher economic value compared with compost derived from traditional composting methods. Composting requires additional space for curing, whereas vermicasts can be packaged and marketed either 
immediately or after a 2-week nitrification period where microbial activity resurges in the casts and ammonium in the earthworm's casts is nitrified. Also, at the optimal density of 150 earthworms/liter of waste, the residence time is almost constant at 20 to 30 days, depending on the waste density, whereas composting requires about 3 months and 1 to 4 months of curing.

Traditional batch type or non-continuous vermicomposting is done in a bed measuring $1 \times 5$ meters or larger with wooden or concrete sidings. Compost pile is $2 \mathrm{ft}$. high and water is added daily to increase moisture to at least 50 to 70 percent (Guerrero, 2004). Harvesting is done mechanically using sieving equipment to segregate cast and the worms. Worms gathered will be used again to convert new substrates added to the bed.

Various innovations of bed designs were seen in recent years worldwide. These include both patented and unpatented vermicomposting systems. In the Philippines, automated vermicomposting was developed by Macabuhay, Abellera and Ticsay (2016). The study uses Arduino uno and Arduino mega microcontrollers, an android phone, and liquid crystal display (LCD) for monitoring. It was claimed that the automated project improved the manual process of vermicomposting by eliminating four (4) processes: irrigation, sensor network, worm migration, and communication subsystem to minimize human intervention. However, the design did not eliminate the burden of harvesting vermicast since the automated bed they tested could not collect vermicompost leachate.

Vermicompost leachate (VCL) was diluted to 50 percent and mixed with $170 \mathrm{~g} \mathrm{~L}^{-1}$ NPK resulted in best maize plant development in the study conducted by Gomez, Dendooven and Miceli (2008). A similar study was conducted by Avila-Juarez et al. (2014) which found out that VCL had a positive effect on the production of lycopene in tomato; the 
VCL decreased the presence of ions phytotoxic to plants by 99 percent and improved the soil structure by increasing the amount of organic matter and hydraulic conductivity.

The need to further enhance conventional beds to fully utilize the potential of vermicomposting technology was sought to be addressed by the study, as it aimed to develop a mechanical vermicomposting bed with automated harvester and watering system to enhance production.

Specifically, the study aimed to design the component parts of the vermibed production, harvesting and control systems; measure the average daily vermicast and VCL collected; determine the effect of varying levels of moisture content, mesh screen size and sieving speed on harvesting capacity, purity and separation efficiency; and perform cost and return analysis.

\section{Methodology}

Figure 1 shows the procedural framework of the study. The study started with the design phase which included visitation of vermiculture farms and review of literature. Fabrication took place after the design was crafted. Pretesting and modifications were conducted before the final evaluation of the design. Data were gathered and analyzed using Statistical Tool for Agricultural Research (STAR) Version 2.0.1 free software to generate results. 


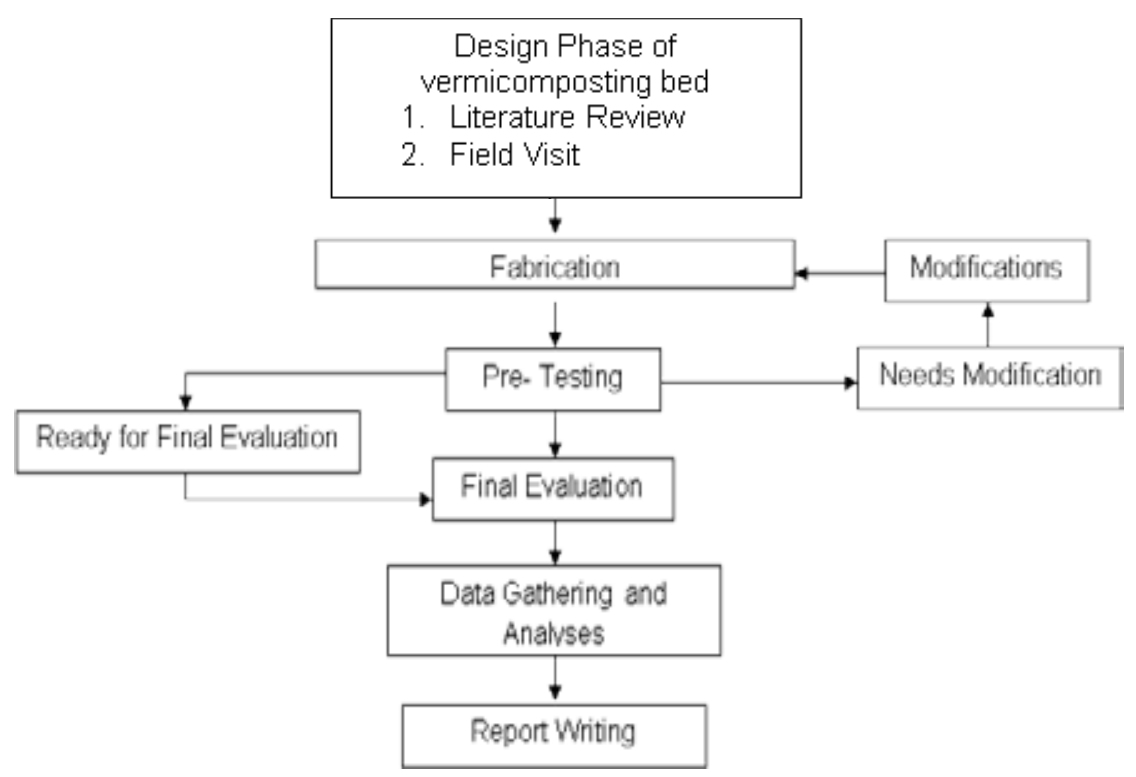

\section{Figure 1}

The procedural framework

\section{Conceptual Design}

Conceptualization of the machine began with reviewing related literature. Basically, the machine adapted some practices and pooling them to produce a new way of harvesting. The composting bin/bed was designed for a continuous flow-through bin, which allows the worms to leave their rich worm castings below as they eat the decaying matter starting from the bottom going up to the top. The worms never travel up and down. They stay right where they like it, most especially where the food is (Rhoads and Anderson, 2009). In the mechanical part of the machine, the study adapted the method of screening. Screening method is the easiest way of separating the worms from their cast. Since they were not manually operated, the screens were attached to a transmission system and driven by motor which caused the screens to move back 
and forth (reciprocating sifters). Scrapers were then attached to the reciprocating sifters in order to scrape the cast of the worms at the bottom portion. These fabricated scrapers helped in holding the worms from falling down into the screens. To ease the production of cast, automated watering and harvesting were integrated. Dripping collector was also incorporated to utilize the leachate during watering.

Figure 2 presents the prototype. Description of the components of the prototype are presented in Table 1.

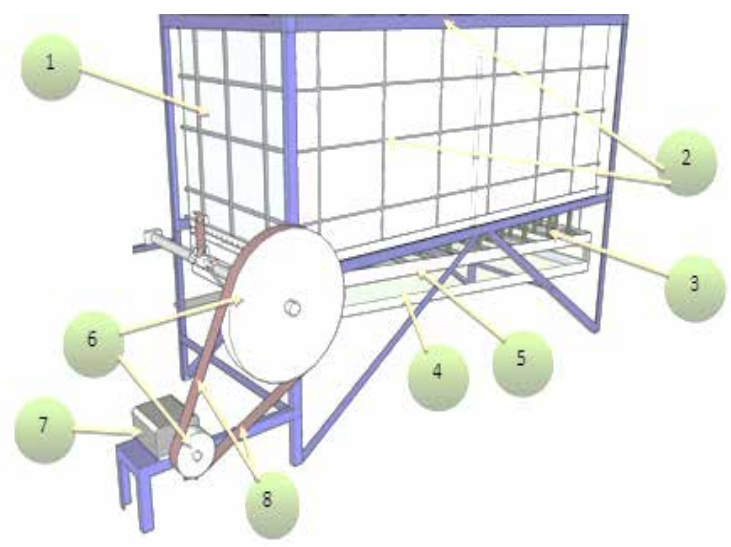

Figure 2

Design of the prototype

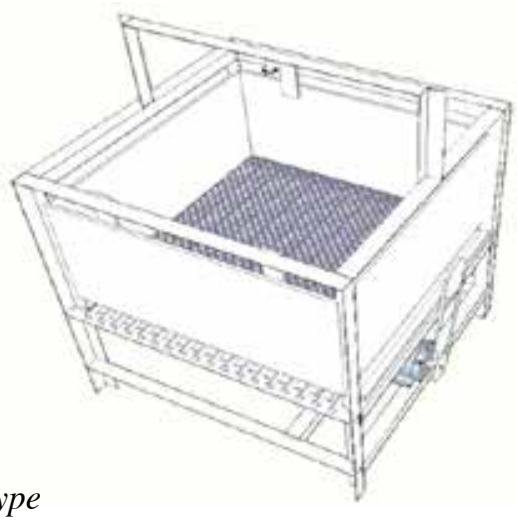


Table 1. Parts and their description

\begin{tabular}{|c|c|c|}
\hline No. & Parts & Description \\
\hline 1 & Container & $\begin{array}{l}\text { A } 1000 \text { L IBC tank utilized for worms with bedding } \\
\text { materials composed of cow's dung, office papers and } \\
\text { dry leaves }\end{array}$ \\
\hline 2 & Frames & $\begin{array}{l}\text { Welded with } 2 \text { " } \times 2 \text { " } \times 3 \text { mm angle bar where the } \\
\text { container is attached inside }\end{array}$ \\
\hline 3 & Scrapers & $\begin{array}{l}\text { Composed of } 6 \mathrm{~mm} \text { round bars welded and fixed in } \\
\text { the siever's frame }\end{array}$ \\
\hline 4 & Sieves & $\begin{array}{l}\text { Made of wood-framed screens with different sizes } \\
\text { such as no. } 12 \text { mesh screen, no. } 6 \text { mesh screen and } \\
1 / 4 \text { mesh screen }\end{array}$ \\
\hline 5 & Sifter's Frame & $\begin{array}{l}\text { Made of welded steel in order to hold the sieves and } \\
\text { where the scrapers were fixed }\end{array}$ \\
\hline 6 & Pulleys & $\begin{array}{l}\text { These pulleys are attached in the system with differ- } \\
\text { ent sizes such as } 16 \text { "x1" pulley, } 4 \text { "x3/4" pulley and } \\
2 \text { "x3/4" }\end{array}$ \\
\hline 7 & Electric Motor & A 1-hp motor with 3/4" diameter shaft \\
\hline 8 & V-belts & $\begin{array}{l}\text { Used in connecting the two pulleys, the pulley from } \\
\text { the motor and the pulley in the system }\end{array}$ \\
\hline 9 & Divider & $\begin{array}{l}\text { This was created for migration of worm purposes and } \\
\text { for experimental purpose }\end{array}$ \\
\hline 10 & Shaft & $\begin{array}{l}\text { Connected to the pulley in order to provide } \\
\text { mechanical motion to the connecting mechanism }\end{array}$ \\
\hline 11 & $\begin{array}{l}\text { Connecting } \\
\text { Mechanism }\end{array}$ & $\begin{array}{l}\text { Sieve frame connected in order to create scraping } \\
\text { motion and sieving motion }\end{array}$ \\
\hline 12 & Stairs & $\begin{array}{l}\text { These were created for the convenience of the } \\
\text { operator to check the worm's condition and the ease } \\
\text { of changing the bedding materials }\end{array}$ \\
\hline 13 & Sprinkler & Timer-based sprinklers \\
\hline
\end{tabular}

\section{Experimental Design}

The study was laid out in a Factorial Experiment arranged in a Complete Randomized Design (CRD). The factors considered were Factor 1: Speed (200 rpm and $310 \mathrm{rpm}$ ), Factor 2: Screen Size (no. 12 
mesh, no. 6 mesh and 1/4 mesh), and Factor 3: Moisture Content (40\%, $45 \%$ and $50 \%$ ). Treatment combinations were replicated three (3) times with time as replication.

\section{Description of the Substrate}

The prototype bed was loaded with harvestable substrates 0.46 meters depth with an estimated 30:1 CN ratio. The ratio used was found to be the optimum in the study conducted by Shrimal et al. (2010). Substrate was a mixture of $175 \mathrm{~kg}$ cow's dung at around 30 percent moisture content and $5 \mathrm{~kg}$ ipil-ipil leaves (excluding branches) with papers as bedding materials. Prior to mixture, individual substrate was shredded using mechanical shredder and stored separately in a container for about three weeks to become partially decomposed. The mixed substrates weighed $180 \mathrm{~kg}$ initially, which were loaded to the prototype bed. The worm used was African night crawlers (Eudrilus eugeniae) with initial stocking density of $1.60 \mathrm{~kg} / \mathrm{m}^{2}$. Based on the prototype's dimension, $1.20 \mathrm{~kg}$ of worms was needed. Almost the same type of substrate and proportion were used in all treatment combinations.

\section{Performance Test Procedure}

Experiment was done indoor or inside the building to control environmental condition as watering, aeration and temperature. Three similar prototypes were each assigned with screen mesh size factor. Partially decomposed mix substrates were loaded to each prototype's bed with randomly selected screen mesh size (no. 12 mesh, no. 6 mesh, and 1/4 mesh). Loaded test substrates were also mixed with $1.20 \mathrm{~kg}$ African night crawlers. A predetermined volume and duration of automatic watering corresponding to $40 \%, 45 \%$ and $50 \%$ moisture were set and maintained daily for each prototype's bed. Monitoring of moisture content was 
measured using portable moisture meter (wet volume basis) before watering. Watering was applied every 8:00 am, 12:00 noon and 4:00 pm. Daily vermicast and VCL automatically collected at the bottom of the bed were measured and recorded. At the end of four (4) to five (5) days observation, harvesting of vermicast was done using the desired mesh screen speed (210 rpm and $310 \mathrm{rpm}$ ). Observation for each treatment combination lasted for four (4) to five (5) days to measure the harvesting capacity and separation efficiency of the prototype at varying levels of substrate moisture content, screen mesh size, and speed. Treatment combinations were replicated three (3) times with time as replication. At the end of each treatment combination experiment, uneaten substrate at the composting bed was added with new substrate at the top of the bed. Old and new substrates were used for the next treatment experiment with variation of new watering amount and mesh screen speed. The same process was also used for the rest of the treatment combinations.

\section{Performance Verifiable Indicators}

Vermicast output. This is the total average cast collected and recorded within the day period from natural dropping and activity of African night crawler. Collection was done before 8:00 am prior to the application of watering. Collected vermicast were weighed and moisture content was determined using the sample collected from the treatment with the highest output. VCL was also collected and volume was determined.

Chemical and physical properties. Samples of the harvested vermicast and VCL were sent to the Bureau of Soils and Water Management (BSWM) in Davao City for N-P-K content and physical analysis. These samples were taken from collected average daily vermicast drops beneath the bed, which were air dried prior to submission. Although some research findings revealed that curing for a number of period enhances 
quality of cast, the study did not take it to consideration. On the other hand, VCL collected was stored in 1.5 liters soda bottle. Samples that were sent to the BSWM were a mix of samples taken from each treatment combination. Chemical and physical properties of the vermicast and VCL were highly dependent on the substrate. Since substrate was the same throughout the duration of the study, only one trial was sent to BSWM with three samples analyzed.

Havesting capacity. It is the weight of vermicast collected per unit time during harvesting operation expressed in grams per second $(\mathrm{g} / \mathrm{s})$. Harvesting was done every $4^{\text {th }}$ day or $5^{\text {th }}$ day counting from initial loading of partially matured substrate or when majority of the waste substrate visibly turned into vermicast. This was a signal or basis that another batch of new substrate has to be loaded at the top of the bed so that worms will migrate to upper part while bottom part is ready for harvesting operation. Moisture content of the harvestable vermicast was measured and checked using portable moisture meter every treatment combination before harvesting operation. During harvesting operation, three samples were taken for each treatment combination. These samples were taken after 2-min, 4-min and 6-min time of operation. The time duration of each sample was 10 seconds per collection. Collected sample was then weighed and the harvesting capacity was computed. Weights of all vermicasts were corrected or adjusted to $40 \%$ moisture content (see Equation 1) to ensure that moisture contents would not affect the weights of the vermicasts.

$$
W f=W i \times \frac{100-M C_{i}}{100-M C_{f}}
$$

Equation 1.

where:

$\mathrm{Wf}=$ Corrected Weight at $40 \%$ moisture content

$\mathrm{Wi}=$ Weight at current treatment moisture content $(50 \%$ and $45 \%)$

$\mathrm{MCi}=45 \%$ and $50 \%$ moisture content

$\mathrm{MCf}=40 \%$ moisture content 
Separation efficiency. This refers to the ratio of fine vermicast harvested over the total amount of worms, vermicasts and substrate materials collected below the siever. Samples used in determining separation efficiency were taken from samples used during the determination of harvesting capacity. Samples collected for each treatment combination were weighed to determine the total amount of harvested materials. Manual picking of foreign materials mixed in the cast was done to determine the weight of fine vermicasts harvested.

Purity. This is the weight of the vermicast free from foreign matters and worm over the total weight of sample collected, expressed in percent. Three samples were collected beneath the vermibed during harvesting operation. Foreign matters and African nightcrawler (earth worm) from each sample approximately 500 grams were manually separated through visual inspection. Percentage pure vermicast was then computed and recorded.

\section{Statistical Analysis}

Analysis of Variance (ANOVA) was used to analyze the effect of varying levels of vermicast moisture and harvesting design on the harvesting capacity and quality of the vermicast. Tukey test was also used to compare the means of each factor attribute.

\section{Results and Discussion}

\section{Major Components of the Vermi Bed}

Figures 3 to 13 showed the major components of the automated vermicomposting bed prototype. These are composed of the vermibed production system, harvesting system and control system. 

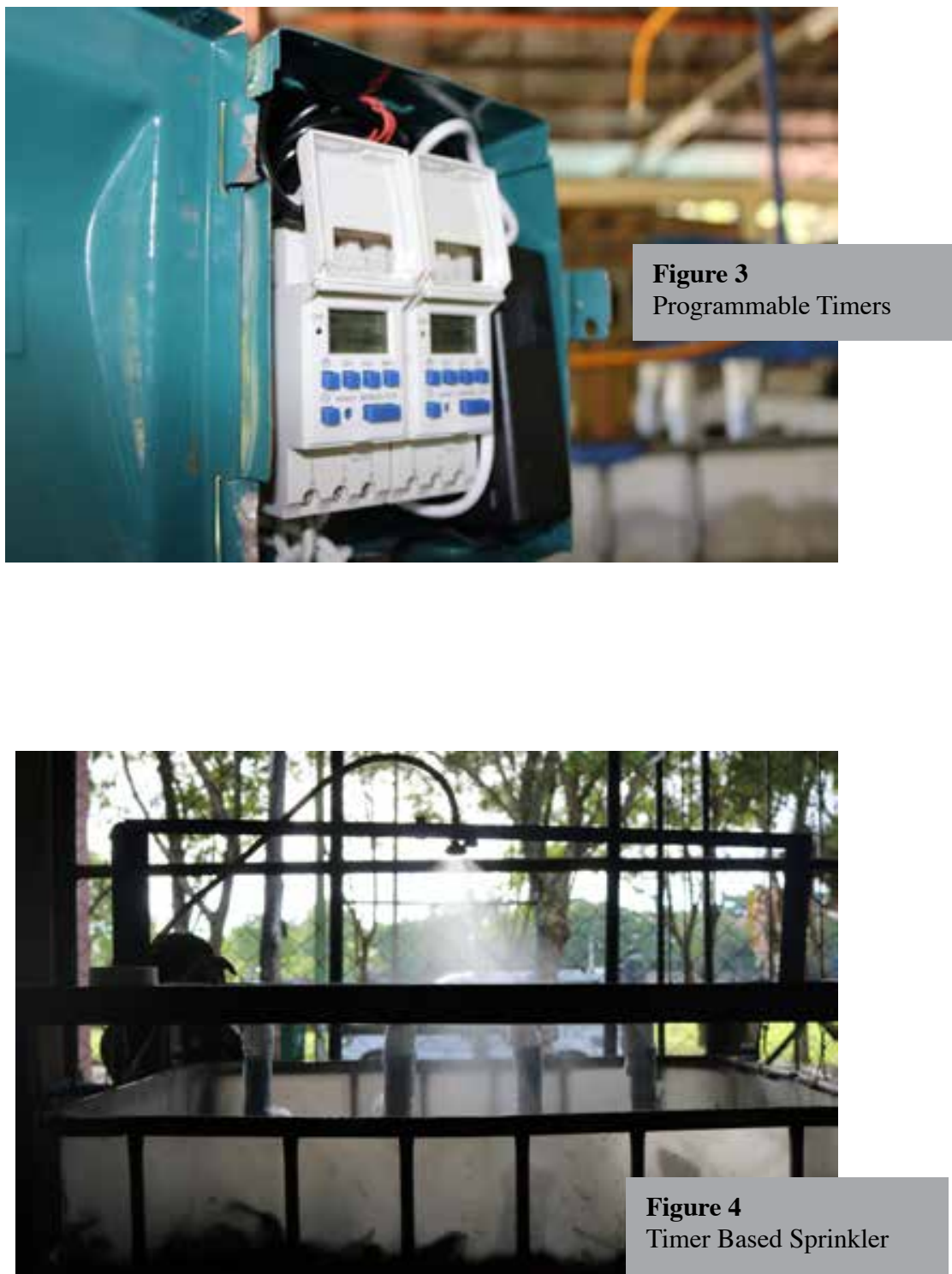

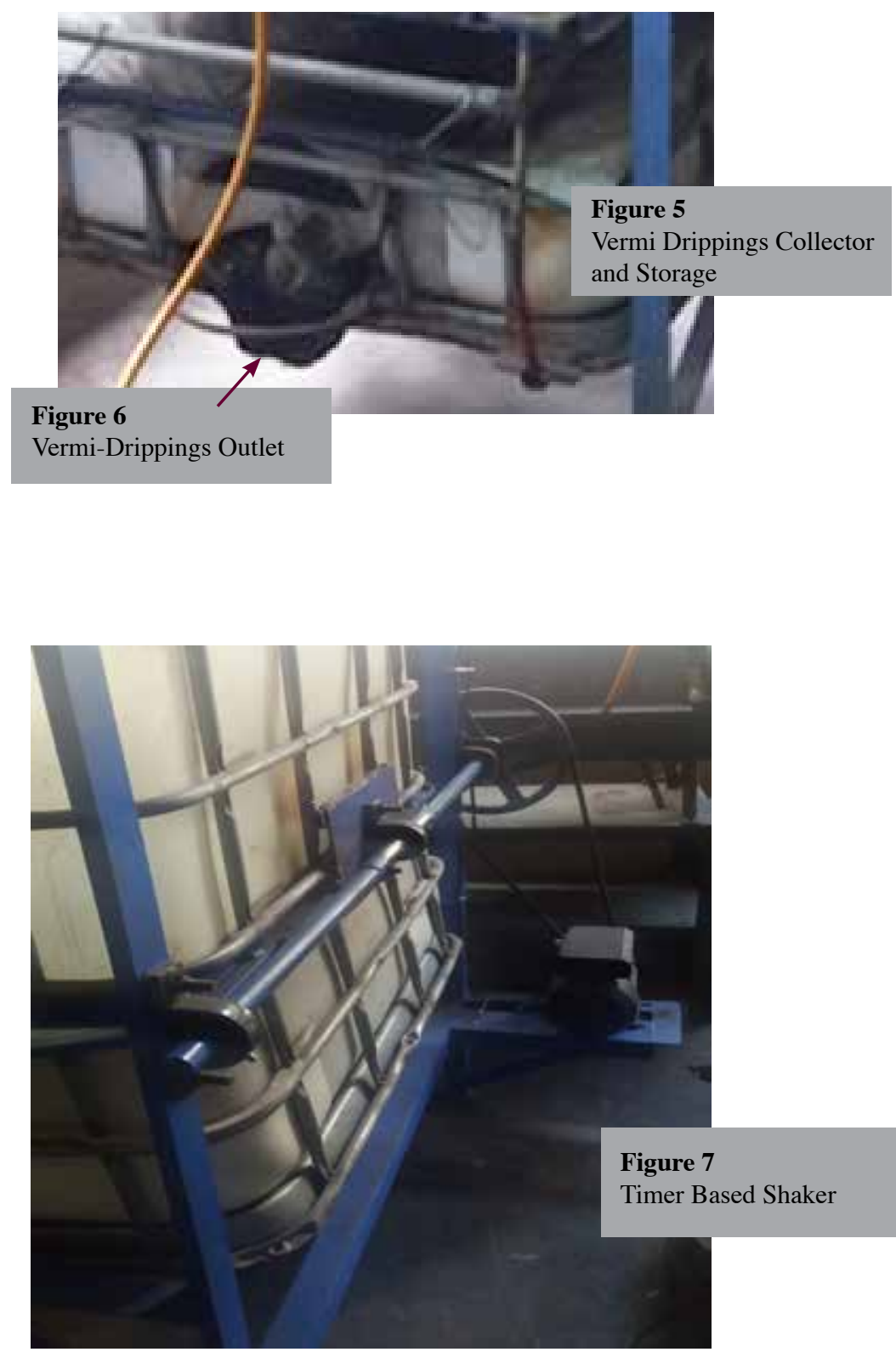

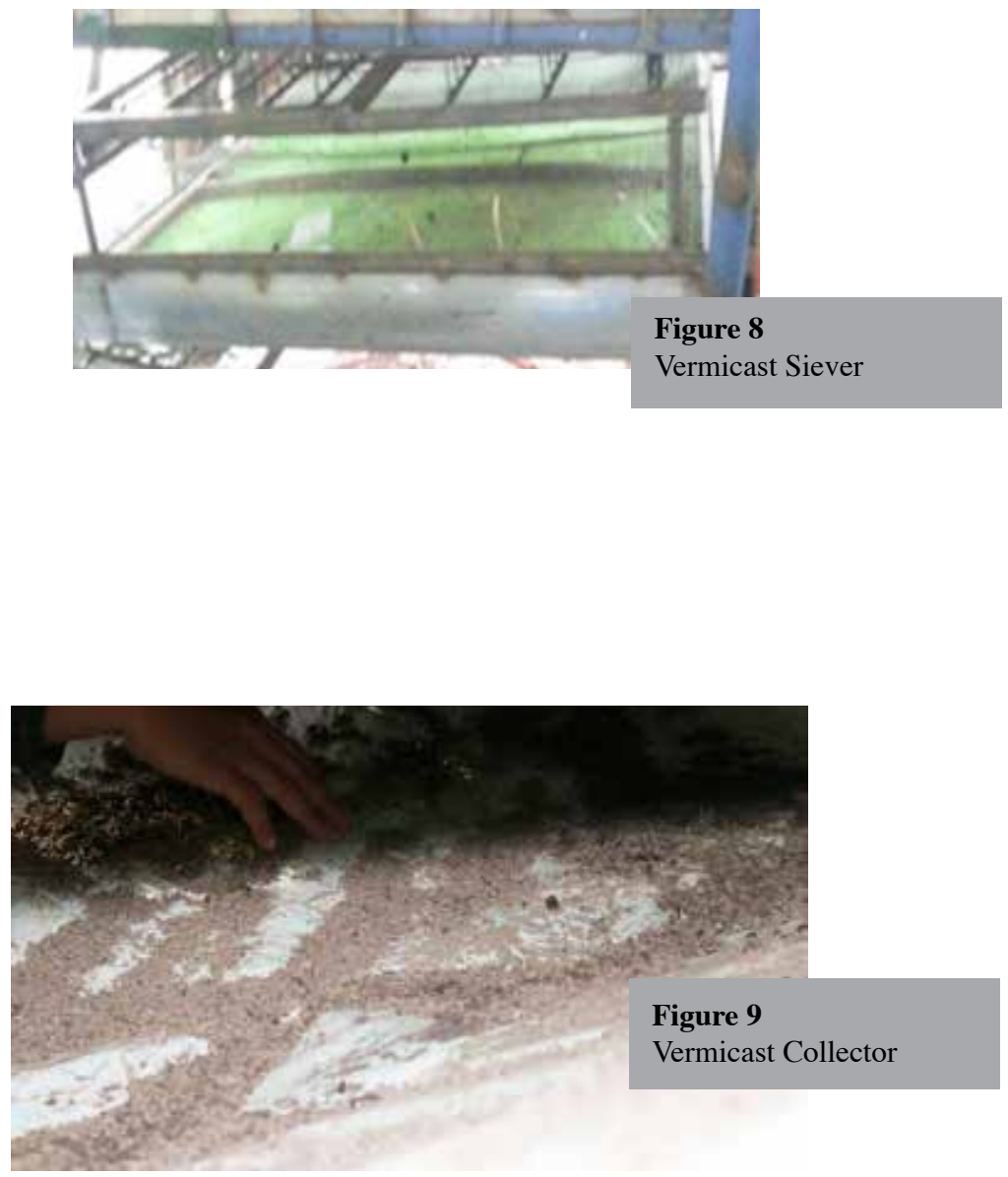

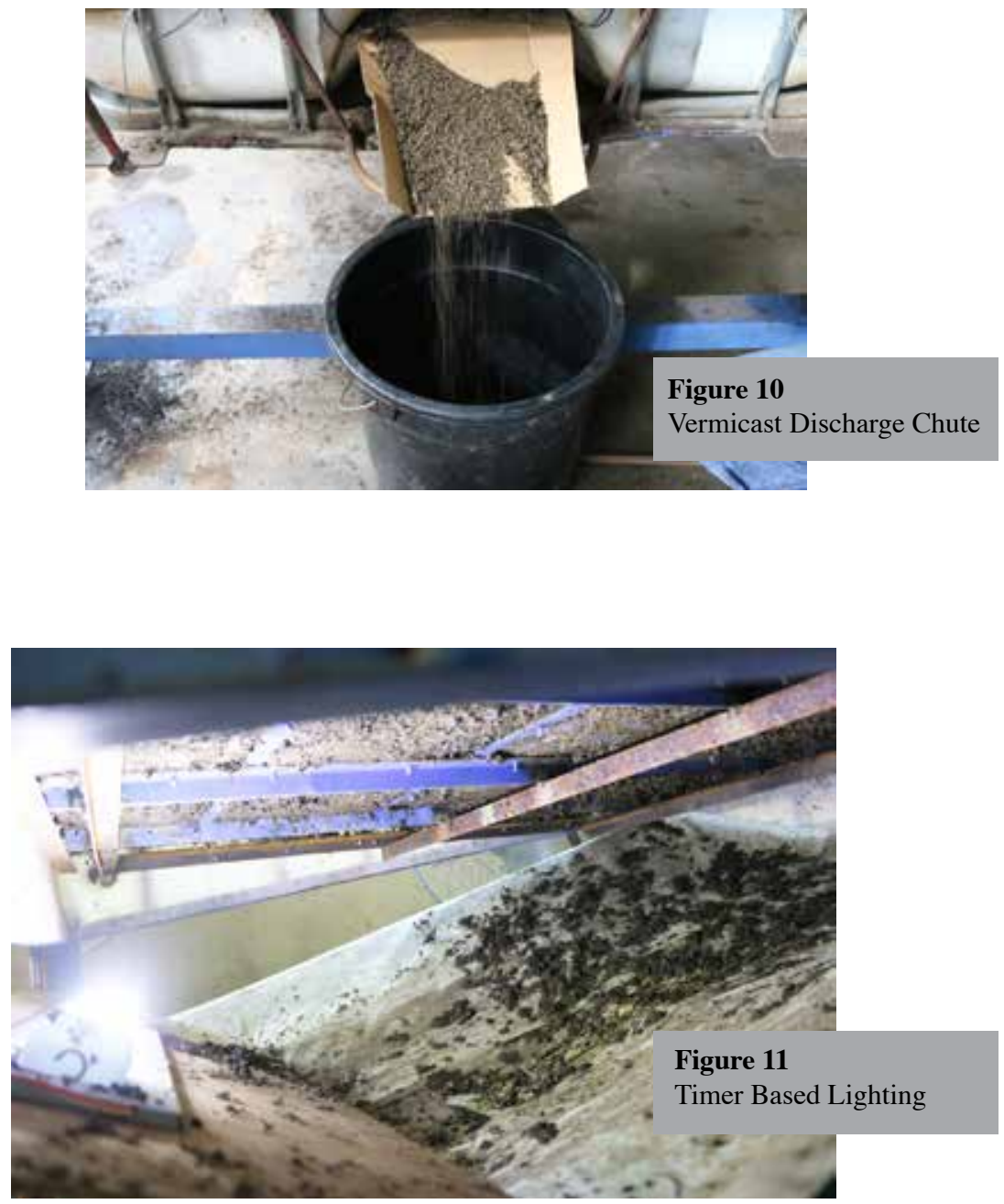

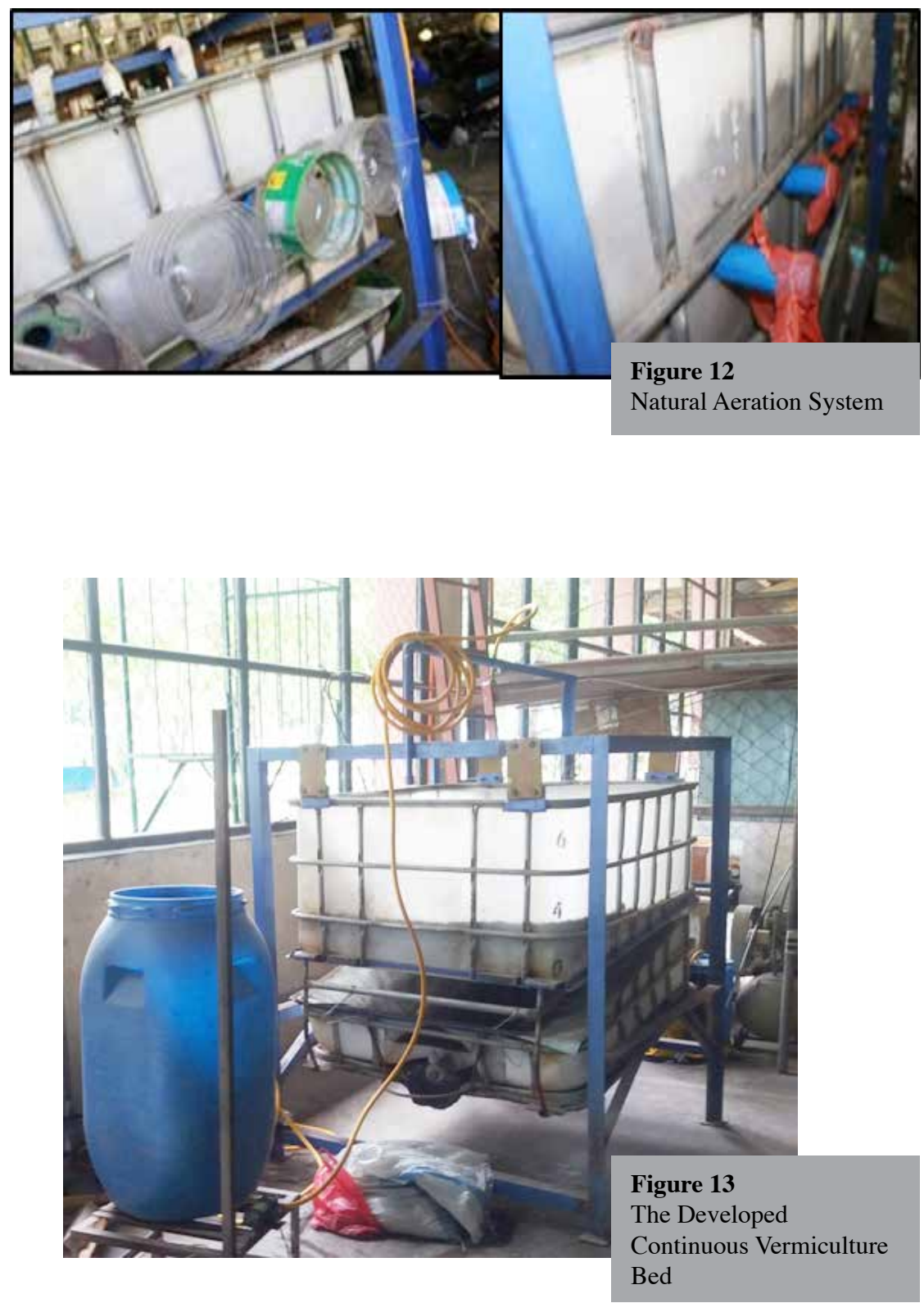
The following are the functions of each component of the automated vermicomposting bed with built-in automated harvester and watering:

1. Programmable Timers - used to automatically water the bed three times a day, harvest the cast daily or weekly, and light the bottom of the bed to keep the worm in the bin.

2. Timer Based Sprinkler - waters the bed to keep the recommended moisture of the bed (60-80\%).

3. Vermi-drippings Collector and Storage - collects and stores excess water (dripping which was proven to be a good liquid organic fertilizer and pesticide/fungicide) during watering.

4. Vermi-drippings Outlet - discharges the stored dripping to any container.

5. Timer Based-Shaker - creates a shaking action to drop cast accumulated in the lower part of the bin. It was driven by a $1 \mathrm{Hp}$ electric motor.

6. Vermicast Siever and Scraper - scrapes cast at the bottom of the bed and separates cast from worm

7. Vermicast Collector - catches the cast that drops before and during harvesting.

8. Vermicast Discharge Chute - delivers the harvested cast from the bin to any container.

9. Timer Based Lighting - switches on during and after watering to keep the worm from going down with the drippings and during harvesting to keep them from going down with the cast.

10. Natural Aeration System - keeps the bin aerated and dissipates internal heat from the shredded substrates. 


\section{Cast, Worm and Leachate Collected}

The factors screen mesh size and sieve speed did not affect the amount of cast, worm and leachate collected. After one (1) week of adding substrate, the automated harvester collected an average of $4 \mathrm{~kg}$ per day or $120 \mathrm{~kg}$ per month between 40 to 50 percent moisture content. Without shaking, vermicast was collected beneath the bed it was freely dropped due to the weight of substrate and worm activity. Five liters of vermicompost leachate were also collected each day. An average increase of 800 grams/month of worm was recorded.

\section{Harvesting Capacity}

Analysis of variance showed that all factors significantly affected the harvesting capacity. Highest speed, largest sieve size and lowest moisture had the largest capacity. However, there was no interaction effect among the three factors on harvesting capacity. Interaction effect was only observed between speed and screen size, and between speed and moisture content. Table 2 shows the average harvesting capacity at varying levels of speed and levels of screen size. It clearly shows that $310 \mathrm{rpm}$ had the larger mean capacity obtained than $200 \mathrm{rpm}$. It can be observed also that among the sizes of sifters, 1/4 mesh screen size had the larger mean capacity obtained than the other sifters. The highest mean value was $48.89 \mathrm{~g} / \mathrm{s}$ while the lowest mean value was $23.19 \mathrm{~g} / \mathrm{s}$.

On comparing harvesting capacity at varying levels of speed and level of moisture content, it was observed that the highest mean value was $74.41 \mathrm{~g} / \mathrm{s}$ attained at 40 percent moisture content with $310 \mathrm{rpm}$. The lowest mean value was $21.01 \mathrm{~g} / \mathrm{s}$ observed at 50 percent moisture content with $200 \mathrm{rpm}$ (see Table 3). 
Table 2. Average harvesting capacity $(\mathrm{g} / \mathrm{s})$ at varying levels of speed and level of screen size

\begin{tabular}{rlcc}
\hline \hline & \multicolumn{4}{c}{ Screen Sizes (R) } \\
\cline { 2 - 4 } Speed (S) & no. 12 & no. 6 & $1 / 4$ \\
\hline $200 \mathrm{rpm}$ & $23.19 \mathrm{bB}$ & $25.52 \mathrm{aB}$ & $46.25 \mathrm{aA}$ \\
\hline $310 \mathrm{rpm}$ & $39.32 \mathrm{aB}$ & $42.30 \mathrm{aA}$ & $48.89 \mathrm{aA}$ \\
\hline \hline
\end{tabular}

The averages followed by the same letter do not differ statistically between themselves (Tukey's HSD, $\mathrm{p}<.005)$.

Legend:

Small letters indicate comparison of speed

Capital letters indicate comparison of screen sizes

Table 3. Average harvesting capacity at varying levels of speed and level of moisture content $(\mathrm{g} / \mathrm{s})$

\begin{tabular}{cccc}
\hline \hline Speed (S) & \multicolumn{3}{c}{ Moisture Content (MC) } \\
\cline { 2 - 4 } & $40 \%$ & $45 \%$ & $50 \%$ \\
\hline $200 \mathrm{rpm}$ & $45.26 \mathrm{bA}$ & $30.69 \mathrm{bB}$ & $21.01 \mathrm{bC}$ \\
$310 \mathrm{rpm}$ & $74.41 \mathrm{aA}$ & $46.64 \mathrm{bA}$ & $31.41 \mathrm{aC}$ \\
\hline \hline
\end{tabular}

The averages followed by the same letter do not differ statistically between themselves (Tukey's HSD, p<.005).

Legend:

Small letters indicate comparison of speed

Capital letters indicate comparison of moisture

In terms of the comparison of screen size at each level of moisture content (see Table 4), still, the largest mean values were observed at 40 percent moisture content with 1/4 mesh screen size with value at 68.95 $\mathrm{g} / \mathrm{s}$. On the other hand, the lowest mean value was observed at 50 percent moisture content with no. 12 mesh screen size, with value at $21.93 \mathrm{~g} / \mathrm{s}$.

Based on the presented results, 1/4 mesh screen size - the largest hole diameter - had the largest mean value. From Tamil Nadu Agricultural University's researches (2014), 1/4 mesh screen size is usually used during the screening of casts, and it was proven by the data presented that mechanized screening method of cast could perform well. On the other hand, no. 12 mesh screen size had the lowest mean value since it 
had the smallest hole diameter. Harvesting capacity was higher at 310 rpm coupled with any screen size and moisture content compared to lower speed (200 rpm).

In terms of moisture content, capacity was decreasing as the moisture content increases. In Manyuchi and Phiri’s (2013) study, largest capacity was achieved at 40 percent moisture content condition as the vermicast, unprocessed bedding and earthworms could easily be separated. Here, at 50 percent $\mathrm{MC}$, the lowest mean values were recorded since the moisture content at this condition created pressure where the cast would hold together. Therefore, higher moisture levels decreased harvesting capacity as throughput speed and significant balling are expected to occur impeding the machine's effectiveness.

Table 4. Average harvesting capacity at varying levels of screen size and each level of moisture content $(\mathrm{g} / \mathrm{s})$

\begin{tabular}{ccccc}
\hline \hline \multirow{2}{*}{ Screen Size (R) } & \multicolumn{4}{c}{ Moisture Content (MC) } \\
\cline { 2 - 4 } & $40 \%$ & $45 \%$ & $50 \%$ \\
\hline no. 12 & 43.57 & $\mathrm{bA}$ & $31.77 \mathrm{bB}$ & $21.93 \mathrm{aB}$ \\
\hline no. 6 & $66.98 \mathrm{aA}$ & $40.13 \mathrm{abB}$ & $25.04 \mathrm{aC}$ \\
\hline $1 / 4$ & $68.9 \mathrm{aA}$ & $44.10 \mathrm{aB}$ & $31.66 \mathrm{aC}$ \\
\hline \hline
\end{tabular}

The averages followed by the same letter do not differ statistically between themselves. (Tukey's HSD, $\mathrm{p}<.005)$.

Legend:

Small letters indicate comparison of screen size

Capital letters indicate comparison of moisture

\section{Separation Efficiency}

Analysis of variance showed that no significant differences were observed among levels of speed and sifter size except for moisture content. Lowest moisture content has the largest separation efficiency: this was confirmed by the study conducted by Manyuchi and Phiri 
(2013). Further, there was no interaction effect among the three factors on separation efficiency.

Table 5. Comparison of separation efficiency at varying levels of speed and level of screen size (\%)

\begin{tabular}{cccc}
\hline \hline \multirow{2}{*}{ Speed (T) } & \multicolumn{3}{c}{ Screen Sizes (R) } \\
\cline { 2 - 4 } & no. 12 & no. 6 & $1 / 4$ \\
\hline $200 \mathrm{rpm}$ & 31.89 & 37.67 & 30.00 \\
\hline $300 \mathrm{rpm}$ & 18.11 & 22.33 & 26.67 \\
\hline \hline
\end{tabular}

The test of comparison of averages was not applied because the F of interaction was not significant

Table 6. Comparison of separation efficiency at varying levels of speed and level of moisture content (\%)

\begin{tabular}{cccc}
\hline \hline \multirow{2}{*}{ Speed (T) } & \multicolumn{3}{c}{ Moisture Content (MC) } \\
\cline { 2 - 4 } & $40 \%$ & $45 \%$ & $50 \%$ \\
\hline $200 \mathrm{rpm}$ & 37.33 & 31.11 & 31.11 \\
\hline $300 \mathrm{rpm}$ & 24.78 & 20.67 & 18.67 \\
\hline \hline
\end{tabular}

The test of comparison of averages was not applied because the F of interaction was not significant

However, it was found out that there was significant interaction between screen sizes and levels of moisture (Table 7). The highest mean value was observed at 40 percent moisture content with $1 / 4$ mesh screen size, with value at 34.5 percent. The lowest mean value was observed at 50 percent moisture content with no. 12 mesh screen size, with value at 21.17 percent. The result indicates that screen sifter size and moisture content significantly affected the separation efficiency. However, sifter speed had no effect on separation efficiency. 
Table 7. Comparison of separation efficiency at varying levels of screen size and level of moisture content (\%)

\begin{tabular}{|c|c|c|c|}
\hline \multirow{2}{*}{ Screen Size (R) } & \multicolumn{3}{|c|}{ Moisture Content } \\
\hline & $40 \%$ & $45 \%$ & $50 \%$ \\
\hline no. 12 & $27.17 \mathrm{aB}$ & $22.00 \mathrm{aB}$ & $21.17 \mathrm{bB}$ \\
\hline no. 6 & $31.83 \mathrm{aA}$ & $24.33 \mathrm{bB}$ & $22.00 \mathrm{aB}$ \\
\hline $1 / 4$ & $34.50 \mathrm{aA}$ & $34.17 \mathrm{aA}$ & $28.33 \mathrm{aA}$ \\
\hline
\end{tabular}

The averages followed by the same letter do not differ statistically

(Tukey's HSD, p<.005)

Legend:

Small letters indicate comparison of screen size

Capital letters indicate comparison of moisture

There was no significant difference with the mean values of speed at different levels of moisture content and sifter possibly because the speeds tested were so fast. Speed lays responsibility in the performance of the machine provided that the proposed harvester has reciprocating sifters and speed suits the machine. Also the vermicomposting bed was the first ever machine that has built-in bin.

\section{Purity of Cast}

In the study, the lowest value of purity was $95.9 \%$ while the highest percentage of purity was $99.9 \%$. Computed values were almost close to $100 \%$ pure cast with a range of $.01 \%$ to $4.1 \%$ impurities. The machine was capable of producing pure vermicast. 


\section{Cast and VCL Quality}

Results of the analyses reveal that total NPK was 3.09\% - with $1.35 \%$ total nitrogen, $0.92 \%$ phosphate and $0.82 \%$ potassium. The total percentage of NPK was within the standard NPK content by PNS/ BAFS 40:2016 or the Philippine National Standards for Organic Soil Amendments which ranges from 2.5\%-5\%. VCL had no total N based on the result but it had $0.025 \%$ phosphate, $0.027 \%$ calcium and $0.0125 \%$ magnesium. VCL was reported to stimulate maize growth (Gomez et al., 2008). The chemical content of the yield is highly dependent on the substrate and bedding materials fed to the vermi worm (Rahman, 2017; Sinha, et al., 2010).

Table 8. Laboratory Analysis of Vermicast and VCL

\begin{tabular}{lllllll}
\hline \hline & Total $\mathrm{N}$ & $\mathrm{P}_{2} \mathrm{O}_{5}$ & $\mathrm{~K}_{2} \mathrm{O}$ & $\mathrm{Ca}$ & $\mathrm{Mg}$ & $\mathrm{pH}$ \\
\hline Vermicast & $1.35 \%$ & $0.92 \%$ & $0.82 \%$ & $0.22 \%$ & $0.99 \%$ & 6.1 \\
VCL & $0 \%$ & $0.025 \%$ & $0.06 \%$ & $0.027 \%$ & $0.012 \%$ & 7.8 \\
\hline \hline
\end{tabular}

\section{Cost Analysis}

Cost analysis reveals that the use of the machine for vermicomposting was economically viable. The machine has an internal rate of return of 55 percent. Results also showed that the benefit cost ratio of the machine can reach up to 1.98 if the machine will operate for 3 years (see Table 9). This findings is at par with the result of the study conducted by Devkotaa et al. (2014) on the economics of vermiculture production in Nepal. They found out that the benefit cost ratio of vermiculture production was 1.55 and internal rate of return was at 65 percent. 
Table 9. Cost analysis of operating the vermicomposting machine

\begin{tabular}{ccccccc}
\hline \hline Year & $\begin{array}{c}\text { Total } \\
\text { Costs } \\
(\mathrm{PhP})\end{array}$ & $\begin{array}{c}\text { Benefits } \\
(\mathrm{PhP})\end{array}$ & $\begin{array}{c}\text { Net } \\
\text { Benefits } \\
(\mathrm{PhP})\end{array}$ & $\begin{array}{c}\text { Discount } \\
\text { Factor } \\
(6 \%)\end{array}$ & $\begin{array}{c}\text { Present } \\
\text { Value } \\
(\mathrm{PhP})\end{array}$ & BCR \\
\hline 1 & $20,000.00$ & $15,000.00$ & $(5,000.00)$ & 1.00 & $(5,000.00)$ & 0.75 \\
2 & $3,000.00$ & $21,000.00$ & $18,000.00$ & 0.87 & $15,652.17$ & 1.47 \\
3 & $3,000.00$ & $21,000.00$ & $18,000.00$ & 0.76 & $13,610.59$ & 1.98 \\
& & & & & & \\
Discount Rate $=15.00 \%$ \\
NPV = 24,262.76
\end{tabular}

Assumptions:

- The following factor levels were used: speed $=310 \mathrm{rpm}$, screen size $=1 / 4$, moisture content $=40 \%$

- The machine on year 1 cannot yield $100 \%$ due to adjustments and tuning needed

- The machine will operate 10 months per year; 2 months are intended for preventive maintenance and cleaning

- Maintenance cost was estimated to be PHP 500 per year (lubricants and screen replacement)

- Price of VCL = PHP 5.00/liter, cast $=$ PHP 300/50 kg, worm $=$ PHP 500/kg

- Substrate cost was computed to be PHP 900 per year (PHP 1 per kilo) and $180 \mathrm{~kg}$ per batch, each batch for a duration of 2 months

- Labor cost (loading and unloading) was estimated to be PHP 900 per year (PHP180 per batch, 5 batches per year)

- $2 \mathrm{man}$-hr/day only during loading of substrate and $0.25 \mathrm{man}-\mathrm{hr} /$ day during production intended for monitoring

- Energy consumption = PHP 1200 for 10 months every year $(8 \mathrm{kWh}$ per month at PHP 15/kWh) 


\section{Summary of Findings}

The prototype vermicompost production was functional and a continuous-bin type. The components are made of steel frame, plastic vermibed, with a 20 -watt pump and a timer control for watering.

The cast and leachate collected per day averaged at $4 \mathrm{~kg}$ and 5 liters, respectively.

Substrate moisture content, size of sifter and shaking speed significantly affected the harvesting capacity. However, only the size of the sifter and substrate moisture content significantly affected the separation efficiency.

Highest capacity was obtained at lowest moisture content, largest sifter size and and highest speed.

Highest separation efficiency was obtained at low moisture content. The prototype had a BCR of 1.97 assuming 3 years of utilization.

\section{Recommendation}

It is recommended to scale up the prototype to improve the benefits derived from it. A study can be conducted on the effect of recirculation of VCL as watering source for the bed (the quality of circulated VCL should be monitored to examine the trend of NPK content). Finally, an increase in worm population should be determined to have an accurate count of worm population and for improved cost analysis. 


\section{References}

Avila-Juarez, L., Rodríguez González, A., Rodríguez Piña, N, GuevaraGonzalez, R.G, Torres Pacheco, I., Ocampo-Velázquez, R.V. \& Moustapha, B. (2014). Vermicompost leachate as a supplement to increase tomato fruit quality. Journal of soil science and plant nutrition. 15. 10.4067/S0718-95162015005000005.

Bhawalkar, V. U., \& Bhawalkar, U. S. (1992). Organic Farming. National Seminar, (pp. 18-19). Pune.

Bureau of Agriculture and Fisheries Standard. (2016). Organic Soil Amendments. Philippine National Standard. Quezon City, Philippines: BAFS.

Edwards, C. A. (1998). The Use of Earthworm to Breakdown and Management of Organic Wastes. In C. A. Edwards, Earthworm Ecology (pp. 327-354). Boca Raton: CRC Press.

Gomez, R. C., Dendoven, L., \& Miceli, F. A. (2008). Vermicomposting leachate as liquid fertilizer for maize (Zea mays L.) Forage Production, Asian Journal of Plant Sciences, 7, 360-367.

Guerrero, R.D. (2004). Handbook of Vermicompost and Vermimeal Production and Utilization. Aquatic Biosystems, Laguna, Philippines.

International Rice Research Institute (IRRI). Statistical Tool for Agricultural Research (STAR) Version 2.0.1 free software.

Loehr, R. C., Martin, J. H., \& Malecki, M. R. (1984). Waste Management Using Earthworms-- Engineering and Scientific Relationships. Washington D.C.: National Foundation. 
Macabuhay, M. A., Abellera, M. T., \& Ticsay, A. E. (2016). Development of an Automated Production of African Night Crawler's Vermicast with Android Application. Proceedings of the World Congress on Engineering Vol I. London: WCE.

Manyuchi, M. M., and A. Phiri. (2013). Effective separation of vermicasts from earthworms using a cylindrical rotary trommel separator. International Journal of Innovative Research in Science, Engineering and Technology 2(8): 4069-4072.

Rahman, A., Mehrdad, J., Elahe, K., \& Mohammad, P. (2017). Effects of raw materials on vermicompost qualities. Journal of Plant Nutrition, 1635-1643.

Rhoads, R., \& Anderson, G. (2009). Patent No. US7998728B2. United States of America.

Shirmal, S., and M. Khwairkpam. Effect of C/N ratio on vermicomposting of vegetable waste. (2010). Dynamic Soil, Dynamic Plant 4 (Special Issue 1): 123-126.

Sinha, R., Agarwal, S., Chaun, K., Chandran, V., \& Soni, B. K. (2010). Vermiculture technology: Reviving the dreams of Sir Charles Darwin for scientific use of earthworms in sustainable development programs. Technology and Investment, 1, 155-172.

Tamil Nadu Agricutural University. (2014). TNAU Agritech Portal Farm Enterprise. Retrieved from http://agritech.tnau.ac.in/farm_ enterprises /Farm\%20enterprises_\%20 vermicompost.html 